American Journal of Environmental Sciences 7 (1): 43-50, 2011

ISSN 1553-345X

(C) 2010 Science Publications

\title{
Landslide Susceptibility Assessment using Frequency Ratio Model Applied to an Area along the E-W Highway (Gerik-Jeli)
}

\author{
Tareq H. Mezughi, Juhari Mat Akhir, \\ Abdul Ghani Rafek and Ibrahim Abdullah \\ School of Environmental and Natural Resource Sciences, \\ Faculty of Science and Technology, \\ University Kebangsaan Malaysia, 43600 UKM Bangi, Selangor, Malaysia
}

\begin{abstract}
Problem statement: The study area is frequently subjected to landslides especially alongside the E-W high way. This study demonstrates the implementation of the Frequency Ratio (FR) model with the aid of GIS tool to assess the contribution of every predisposing factor on landslides and produce a landslide susceptibility map to the area. Approach: A landslide location map of the study area was prepared based on the interpretation of aerial photographs, previous landslide maps and field surveys. In addition, ten relevant thematic maps representing considered factors were extracted from the constructed spatial database. Slope gradient, slope aspect, elevation, distance to road and drainage density, all were calculated from the topographic database; lithology, strata dip map and foliation dip map were generated from the geologic database; lineament density was prepared from Landsat-7 (ETM+) satellite image; and a soil map was prepared from the soil database. Results: relationship between landslides and instability factors was statistically evaluated by frequency ratio analysis. The results suggested that distance to road, lineament density and slope gradient are the most important factors effecting landslides. Frequency ratio values were used to produce the Landslide Susceptibility Index (LSI) with which the study area was divided into five zones of relative landslide susceptibility. Conclusion: The results of the analysis have been validated by calculating the AUC which shows an accuracy of $88.31 \%$ in the case of success rate curve and $84.68 \%$ in the case of the prediction rate curve, indicating a high quality susceptibility map obtained from the FR model. The map could be used by decision makers as basic information for slope management and land use planning.
\end{abstract}

Key words: Frequency Ratio (FR), landslide causative factors, landslide susceptibility, East-West highway, Landslide Susceptibility Index (LSI), Digital Elevation Model (DEM), Triangulated Irregular Network (TIN), Unified Soil Classification System (USCS), Plasticity Index (PI), Liquid Limit (LL), Area Under a Curve (AUC)

\section{INTRODUCTION}

Landslides are among the most costly and damaging natural hazards in the mountainous terrains of tropical and subtropical environments, which cause frequently extensive damage to property and occasionally result in loss of life. Over the last three decades, numerous efforts have been devoted by many researchers to develop landslide susceptibility maps. These maps describe areas where landslides are likely to occur in the future and classify those areas into different susceptibility zones from very low to very high susceptible zones according to their susceptibility to landslides. Such as landslide susceptibility maps are useful for planners and developers to choose favorable locations for future developments. Roads are the main type of transportation system in Malaysia. About 30\% of these roads traversed through or located in hilly and mountainous areas (Jamaludin et al., 2006). During the last two decades landslides are events have increased in Malaysia, especially on cut slopes and on embankments alongside roads and highways in mountainous areas. From 1993-2004, there were 13 major landslides reported in Malaysia, involving both cut and natural slopes with a total loss of more than 100 lives (Huat and Suhaimi, 2005). These landslides which damage roads and highways are still a special problem in Malaysia, that requires more attention of engineers and geologists in order to prevent them and mitigating their effects.

Corresponding Author: Tareq H. Mezughi, School of Environmental and Natural Resource Sciences, Faculty of Science and Technology, University Kebangsaan Malaysia, 43600 UKM Bangi, Selangor, Malaysia 
Am. J. Environ. Sci., 7 (1): 43-50, 2011

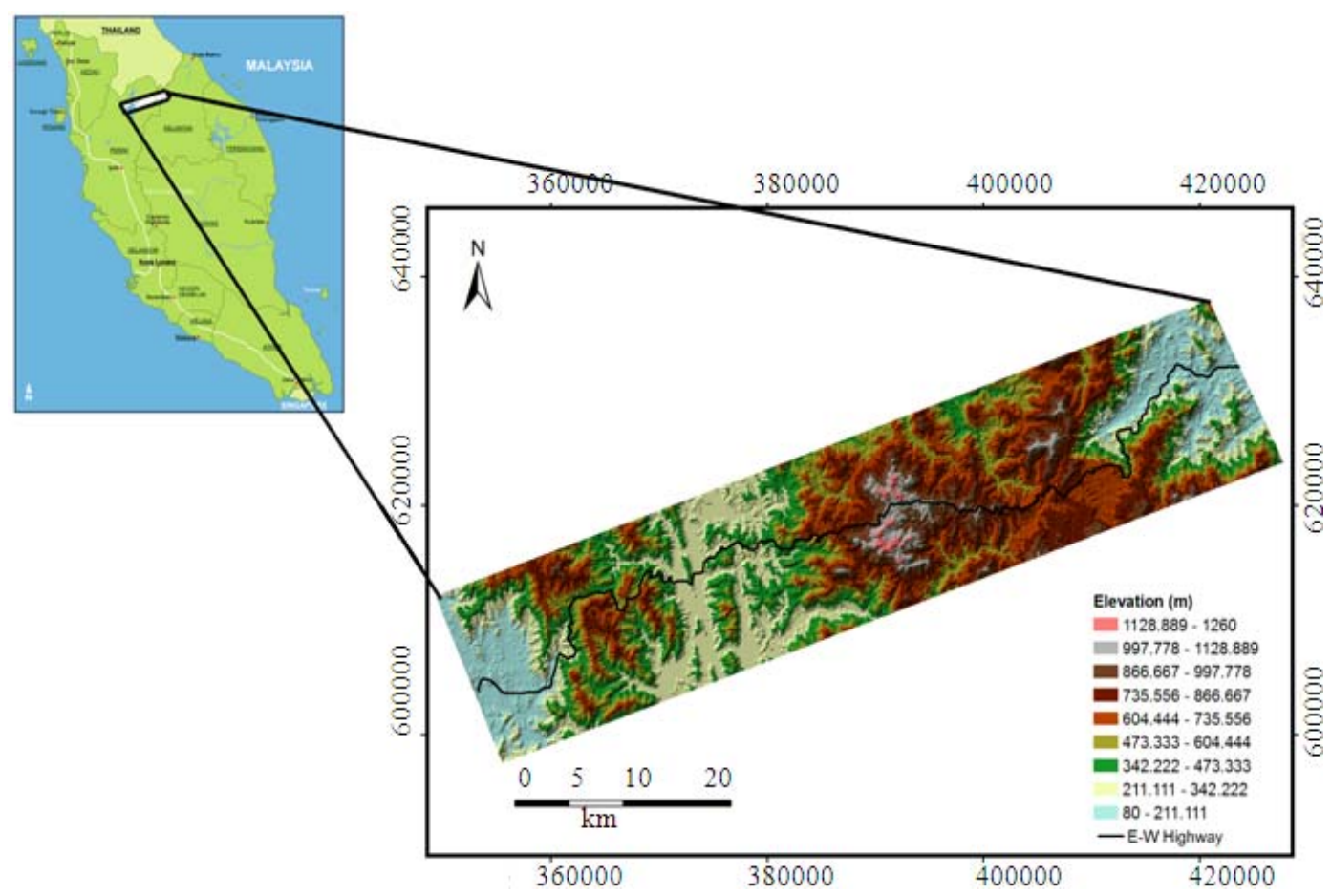

Fig. 1: Location of the study area shown with the TIN map

GIS is an effective tool that is used commonly in landslide susceptibility mapping to identify in advance potential landslide-prone areas, by applying different models and approaches. The two main methods are generally applied to landslide susceptibility assessment are qualitative methods, which are a direct hazard mapping techniques and quantitative methods, which are indirect mapping techniques.

In the literature, there have been many studies applied using probabilistic models (Mancini et al.,2010; Regmi et al., 2010). One of the common multivariate statistical methods applied to landslide susceptibility mapping is the logistic regression model (Nandi and Shakoor, 2010). Frequency ratio method has also been applied (Poudyal et al., 2010; Pradhan, 2010a). Geotechnical model and the safety factor model are quantitative methods used for hazard mapping (Sulaiman and Rosli, 2010). More recently, fuzzy logic and artificial neural network models have also been applied as new landslide susceptibility assessment approaches (Pradhan et al., 2010; Pradhan 2010b).

In this study the frequency ratio model, which is a simple and understandable probabilistic model was used to produce a landslide susceptibility map for the study area and to evaluate the importance of casual factors controlling the landslides.

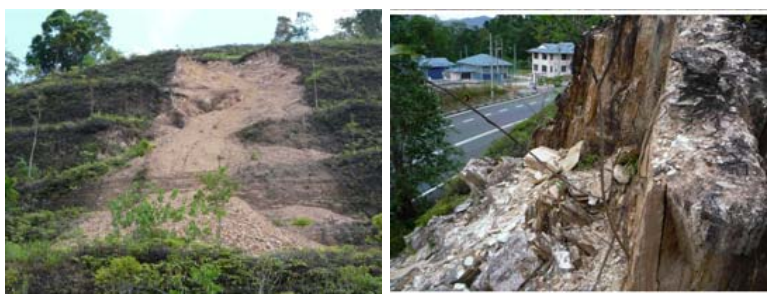

Fig. 2: Photos of landslides in the study area

Study area: The study area is located in the central northern part of Peninsular Malaysia along the E-W highway which has a length of $117 \mathrm{~km}$ and connects the town of Gerik to Jeli. Geographically, it is situated at the co-ordinates between $5^{\circ}: 24^{\prime \prime} 6^{\prime} \mathrm{N}$ to $5^{\circ}: 45^{\prime \prime}: 56.5^{\prime} \mathrm{N}$

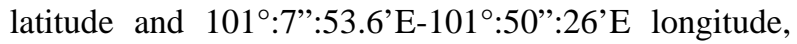
as illustrated in Fig. 1. It covers about $1205 \mathrm{~km}^{2}$, which are characterized by rugged hills and mountain terrains covered by thick rain forest.

The study area is frequently subjected to landslides following heavy rains, especially alongside the high way since it was constructed (Fig. 2). The common types of landslides identified in the area were rock slumps, rock falls, wedge slides, toppling, soil slides and soil slumps.

From the lithological standpoint, the study area is dominated by the three rock types, namely sedimentary, 
igneous and metamorphic. Igneous and metamorphic rocks cover the middle and eastern part of the area while the sedimentary rocks are commonly found in the west. The igneous rocks are mainly composed of granite except a small area at the east end part which is composed of granite, granodiorite and syenite.

The argillaceous rocks represented by the upper Ordovician to lower Devonian Kroh Formation consist of black carbonaceous shale and siliceous mudstone with chert. The arenacous rocks in the eastern part of the area are represented by Kroh Formation (Baling Group) which consist of metarenite with Ordovician to Silurian age, whereas in the western part of the area is represented by the Mangga Beds consisting of metasandstone and metagreywacke of the Permian age. The pyroclastic rocks consist of metatuffs of rhyolitic composition.

The metamorphic rocks, which are strongly foliated, are represented by schist, phyllite, slate and marble. The Tiang Schist which is of Silurian age occurs in the eastern part of the area and consists of mainly quartz-mica schist, quartz-graphite schist, quartz-mica-andalusite schist and minor amphibole schist. In the middle and western parts of the area, metamorphic rocks are represented by argillaceous facies that consist mainly of quartz-chlorite schist, sericite schist, graphitic schist and phyllite.

\section{MATERIALS AND METHODS}

\section{Spatial database preparation using GIS and remote} sensing: To assess landslide susceptibility for an area, it is necessary to identify and map both the instability factors and landslide locations. In this study, a landslides location map was prepared based on interpretation of the aerial photographs and previous studies conducted on the area. In addition, field work has been carried out to map recent landslides. A total of 143 landslides were mapped in the area. The instability factors were chosen based on the two above mentioned studies which were carried out on the study area, the bibliographical review and from field investigations. There were 10 factors considered in contributions to the landsliding process as follows: slope gradient, slope aspect, elevation, lithology, lineaments density, drainage density, strata bedding angle, foliation angle, distances from road networks and soil.

Digital Elevation Model (DEM), which represents the land surface terrain of the area was generated with a
$20 \mathrm{~m}$ grid from the digitized contours at $20 \mathrm{~m}$ interval and survey base points of the 1:50,000-scale topographic maps using the Triangulated Irregular Network (TIN) module of 3D Analyst tool extension on ArcGIS 9.2. Using this DEM, the three topographic parameters, slope gradient map, slope aspect map and elevation map were automatically derived and classified into classes as shown in Table 1 . The drainage map was digitized from the topographic maps of scale 1:50.000 and then the drainage density map was computed considering a $20 \mathrm{~m}$ grid cell and classified into five equal interval classes. Lineaments were traced from visual interpretation of band 4 of Landsat-7 ETM+ image and from filtered images obtained from four directional sobel filters: N-S, NE-SW, E-W and NWSE which were applied to the band 4 of Landsat 7 ETM+ image. The produced lineaments map was then used to compute the lineaments density map. From the lithological point of view, 10 units were digitized from geological maps (scale 1:63,360) obtained from Minerals and Geoscience Department of Malaysia. These units are described in Table 2. Structural information including strata dip and foliation dip, were derived from the same geological maps mentioned above and from field reading. A total of 200 readings representing strata dip and strike and 230 reading representing foliation dip and strike were digitized as points and then they were interpolated to produce strata dip map and foliation dip map. The road distance map was produced by digitizing the road network from the topographic map and classifying the area to five distance buffer classes calculated from both sides of the roads. A soil map was prepared using 32 soil samples collected in the field from residual soils formed by weathering processes on the rocks. In this study the soil were classified according to the Unified Soil Classification System (USCS). The grain size distribution of gravel and sand particles were measured using the sieve analysis. Fine-grained soils, which could be silts or clays, cannot be measured using the sieves therefore they were classified according to their Atterberg limits.The Liquid Limit (LL), Plastic Limit (PL) and Plasticity Index (PI) values of fine-grained soils were determined from laboratory analysis. The values of plasticity index and liquid limit are plotted on a plasticity chart and the fine-grained soils were classified according to its plotting region on the chart (Fig. 3). The two types of soil were identified were SILT-sandy and SAND-silty. 
Am. J. Environ. Sci., 7 (1): 43-50, 2011

Table 1: Frequency ratio values for causative factors

\begin{tabular}{|c|c|c|c|c|c|c|}
\hline Factor & Class & $\begin{array}{l}\text { Number of pixels } \\
\text { in class }\end{array}$ & Class (\%) & $\begin{array}{l}\text { Number of landslide } \\
\text { pixels within the class }\end{array}$ & $\begin{array}{l}\text { Landslides } \\
(\%)\end{array}$ & FR \\
\hline \multirow{6}{*}{ Slope gradient (Degree) } & $0-5$ & 359512 & 11.93 & 125 & 2.03 & 0.17 \\
\hline & $5-15$ & 881937 & 29.28 & 734 & 11.89 & 0.41 \\
\hline & $15-25$ & 760003 & 25.23 & 1563 & 25.33 & 1.00 \\
\hline & $25-35$ & 566765 & 18.81 & 2316 & 37.53 & 1.99 \\
\hline & $35-45$ & 268316 & 8.91 & 1128 & 18.28 & 2.05 \\
\hline & $>45$ & 175997 & 5.84 & 305 & 4.94 & 0.85 \\
\hline \multirow[t]{9}{*}{ Slope aspect } & Flat & 197129 & 6.54 & 30 & 0.49 & 0.07 \\
\hline & $\mathrm{N}$ & 358467 & 11.90 & 924 & 14.97 & 1.26 \\
\hline & $\mathrm{NE}$ & 341436 & 11.33 & 507 & 8.22 & 0.72 \\
\hline & E & 354977 & 11.78 & 674 & 10.92 & 0.93 \\
\hline & $\mathrm{SE}$ & 353078 & 11.72 & 603 & 9.77 & 0.83 \\
\hline & $\mathrm{S}$ & 323966 & 10.75 & 865 & 14.02 & 1.30 \\
\hline & SW & 343649 & 11.41 & 814 & 13.19 & 1.16 \\
\hline & W & 374054 & 12.42 & 682 & 11.05 & 0.89 \\
\hline & NW & 365761 & 12.14 & 1072 & 17.37 & 1.43 \\
\hline Lineament density & $<0.5$ & 1223954 & 40.63 & 492 & 7.97 & 0.20 \\
\hline \multirow{4}{*}{$\left(\mathrm{km} / \mathrm{km}^{2}\right)$} & $0.5-1$ & 776479 & 25.78 & 933 & 15.12 & 0.59 \\
\hline & $1-1.5$ & 736582 & 24.45 & 1265 & 20.50 & 0.84 \\
\hline & $1.5-2$ & 227328 & 7.55 & 1970 & 31.92 & 4.23 \\
\hline & $2-2.5$ & 48174 & 1.60 & 1511 & 24.49 & 15.31 \\
\hline Drainage density & 0.876 & 235122 & 7.80 & 74 & 1.20 & 0.15 \\
\hline \multirow{4}{*}{$\left(\mathrm{km} \mathrm{km}^{-2}\right)$} & 1.752 & 443621 & 14.73 & 1617 & 26.20 & 1.78 \\
\hline & 2.629 & 1359260 & 45.12 & 3183 & 51.58 & 1.14 \\
\hline & 3.505 & 770839 & 25.59 & 960 & 15.56 & 0.61 \\
\hline & 4.382 & 203675 & 6.76 & 337 & 5.46 & 0.81 \\
\hline \multirow[t]{6}{*}{ Bedding angle (Degree) } & $<5$ & 30043 & 1.00 & 0 & 0.00 & 0.00 \\
\hline & 5-15 & 40878 & 1.36 & 0 & 0.00 & 0.00 \\
\hline & $15-25$ & 52828 & 1.75 & 168 & 2.72 & 1.55 \\
\hline & $25-35$ & 97881 & 3.25 & 309 & 5.01 & 1.54 \\
\hline & $35-45$ & 182518 & 6.06 & 435 & 7.05 & 1.16 \\
\hline & $>45$ & 335156 & 11.13 & 986 & 15.98 & 1.44 \\
\hline \multirow[t]{6}{*}{ Foliation angle (Degree) } & $<5$ & 1 & 0.00 & 0 & 0.00 & 0.00 \\
\hline & 5-15 & 8581 & 0.28 & 0 & 0.00 & 0.00 \\
\hline & $15-25$ & 55093 & 1.83 & 78 & 1.26 & 0.69 \\
\hline & $25-35$ & 88086 & 2.92 & 129 & 2.09 & 0.71 \\
\hline & $35-45$ & 81299 & 2.70 & 236 & 3.82 & 1.42 \\
\hline & $>45$ & 571677 & 18.98 & 877 & 14.21 & 0.75 \\
\hline \multirow[t]{5}{*}{ Distance from road (m) } & 100 & 61978 & 2.06 & 3217 & 52.13 & 25.34 \\
\hline & 200 & 54648 & 1.81 & 1419 & 22.99 & 12.68 \\
\hline & 300 & 53503 & 1.78 & 1050 & 17.02 & 9.58 \\
\hline & 400 & 52159 & 1.73 & 6 & 0.10 & 0.06 \\
\hline & 1000 & 2790229 & 92.62 & 479 & 7.76 & 0.08 \\
\hline \multirow[t]{10}{*}{ Lithology } & LU1 & 943735 & 31.33 & 2363 & 38.29 & 1.22 \\
\hline & LU2 & 257974 & 8.56 & 639 & 10.35 & 1.21 \\
\hline & LU3 & 204770 & 6.80 & 383 & 6.21 & 0.91 \\
\hline & LU4 & 462121 & 15.34 & 269 & 4.36 & 0.28 \\
\hline & LU5 & 272449 & 9.04 & 92 & 1.49 & 0.16 \\
\hline & LU6 & 44063 & 1.46 & 121 & 1.96 & 1.34 \\
\hline & LU7 & 504561 & 16.75 & 1172 & 18.99 & 1.13 \\
\hline & LU8 & 243678 & 8.09 & 987 & 15.99 & 1.98 \\
\hline & LU9 & 14466 & 0.48 & 29 & 0.47 & 0.98 \\
\hline & LU10 & 64700 & 2.15 & 116 & 1.88 & 0.88 \\
\hline \multirow[t]{6}{*}{ Elevation (m) } & $<200$ & 348781 & 11.58 & 1001 & 16.22 & 1.40 \\
\hline & $200-400$ & 837488 & 27.80 & 1482 & 24.02 & 0.86 \\
\hline & $400-600$ & 697408 & 23.15 & 1685 & 27.31 & 1.18 \\
\hline & $600-800$ & 750438 & 24.91 & 1249 & 20.24 & 0.81 \\
\hline & $800-1000$ & 299356 & 9.94 & 412 & 6.68 & 0.67 \\
\hline & $>1000$ & 79046 & 2.62 & 342 & 5.54 & 2.11 \\
\hline \multirow[t]{2}{*}{ Soil } & Sand-silty & 2724776 & 90.45 & 5092 & 82.51 & 0.91 \\
\hline & Silty-sand & 287709 & 9.55 & 1079 & 17.49 & 1.83 \\
\hline
\end{tabular}

Landslide susceptibility assessment using frequency ratio model: In this study, the frequency ratio model was applied in order to evaluate quantitatively the landslide susceptibility of the area based on the observed spatial relationship between landslide locations and each predisposing factor. Before the analysis was applied, the original landslide map was divided randomly into two sub-set groups, one with $80 \%$ (114 cases) of the total landslides was used as an estimation group to produce the susceptibility map and the second with 20\% (29 cases) was used for validation of the results.

To evaluate the contribution of each factor towards landslide susceptibility, the landslide estimation group was overlaid with thematic data layers separately then the frequency ratio of each factor's class was calculated in three steps. 


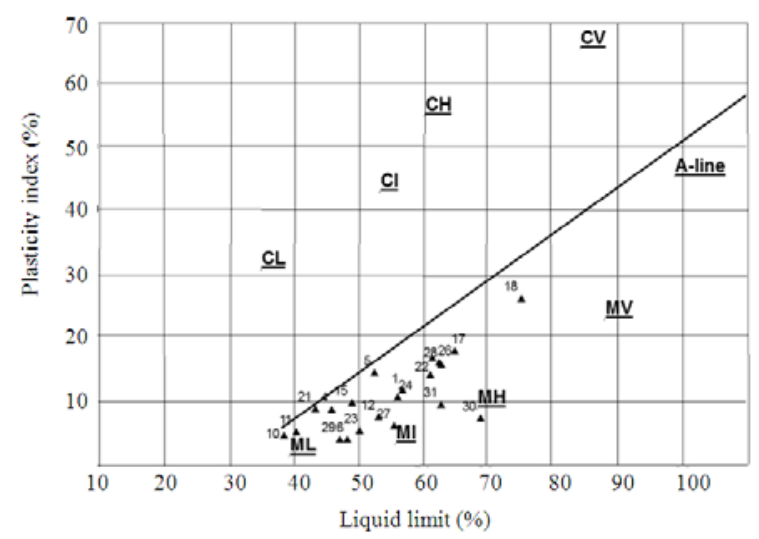

Fig. 3: Plasticity chart showing classification of finegrained soils

Table 2: Lithological units

\begin{tabular}{ll}
\hline Lithological unit & Description \\
\hline LU1 & Granite \\
LU2 & Metagreywacke and metasandstone \\
LU3 & Quartz-chlorite schist, sericite schist, \\
& graphitic schist and phyllite \\
LU4 & Quartz-mica schist, quartz-graphite schist, \\
& and minor amphibole \\
LU5 & Metatuff of rhyolitic composition \\
LU6 & Chert, shale, slate and metasiltstone \\
LU7 & Metarenite \\
LU8 & Phyllite and slate \\
LU9 & Marble with calcereous matesediments \\
LU10 & Granite, granodiorite and syenite \\
\hline
\end{tabular}

First calculating the area ratio for landslide occurrence and non-occurrence in each factor's class, second calculating the area ratio of each factor's class to the total area of the factor. Finally dividing the landslide occurrence ratio by the area ratio for each factor's classes. The obtained ratio values using FR were assigned as weight values to the classes of each factor map to produce weighted factor thematic maps, which were overlaid and numerically added using the raster calculator to produce the Landslide Susceptibility Index (LSI) map using Eq. 1:

$$
\mathrm{LSI}=\mathrm{Wm} 1+\mathrm{Wm} 2+\mathrm{Wm} 3+\ldots \ldots+\mathrm{Wm} n,
$$

Where:

LSI = Landslide susceptibility index

$\mathrm{Wm}=$ Weighted thematic maps of causative factors

The calculated values of FR for each pixel in the LSI indicate the relative susceptibility to landslide occurrence. The higher pixels value of LSI are the higher susceptible to landslides and the lower pixels value are the lower susceptible. In this study, the calculated LSI values were found to be range between 5.48 - 41.51,

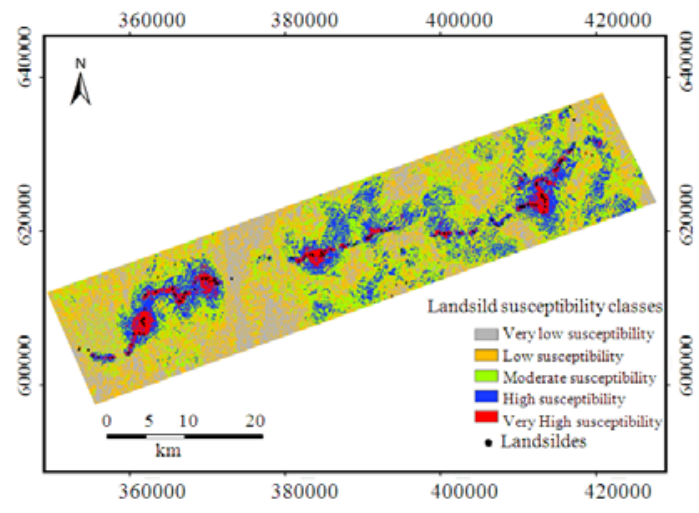

Fig. 4: Landslide susceptibility map of the study area

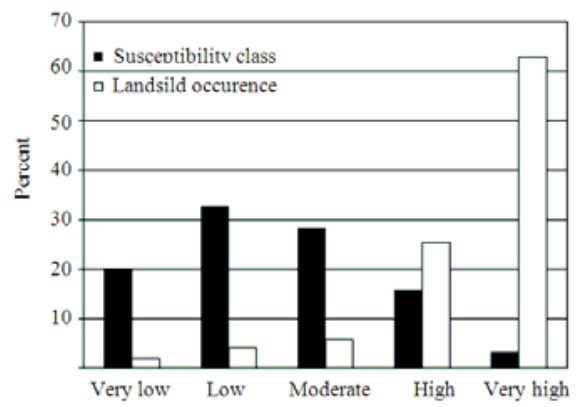

Fig. 5: The percentages distribution of the susceptibility classes and landslide occurrence

which were classified into five classes of susceptibility for visual and easy interpretation (Fig. 4). The percentages of landslide susceptibility classes and the landslide occurrence in each class are shown in Fig. 5.

Verification of the susceptibility map: The landslide susceptibility map of the study area produced by FR model was verified by comparing it with known landslides. The success rate curve (Pradhan and Lee, 2010) was calculated in this study to evaluate the capability of FR model and factors to predict landslides. To generate the success rate curve, the calculated index values of all cells in the study area were sorted in descending order and were divided into 100 equal classes ranging from highly susceptible classes to non susceptible classes. Then the 100 classes were overlaid and intersected with the set of landslides used in constructing the model (estimation landslide group) to determine the percentage of landslide occurrences in each susceptible class. After that the success rate curve was built by plotting the susceptible classes starting from the highest values to the lowest values on the $\mathrm{x}$ axis and the cumulative percentage of landslides occurrence on the Y-axis. 
Am. J. Environ. Sci., 7 (1): 43-50, 2011

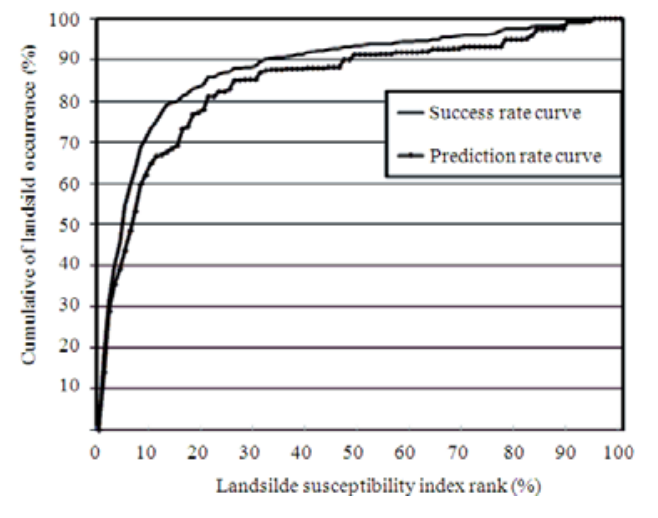

Fig. 6: Cumulative frequency diagram showing percentage of study area classified as susceptible (x-axis) in cumulative percent of landslide occurrence (y-axis)

The susceptibility map was also assessed in terms of its predictive power validity by calculating the prediction rate. The prediction rate curve was prepared using the same data integration and representation procedures of preparing the success rate curve as described above but in this case the validation landslides group was used instead of the estimation landslides group. The rate verification results appear as a line in Fig. 6. The steeper was the line; the better was the capability of the susceptibility map to predict landslides. The result was very satisfactory, the $10 \%$ high susceptible area includes $74.34 \%$ of the total landslide area in the case of success rate curve and $65.78 \%$ in the case of the prediction rate curve, while the $20 \%$ high susceptible area covers more than $84.86 \%$ of the total landslide area in the case of success rate curve and $79.46 \%$ in the case of the prediction rate curve. To assess the prediction accuracy quantitatively the Area Under a Curve (AUC) was used (Poudyal et al., 2010). The area under the curve was recalculated considering the total area equal to 1 , which means perfect prediction accuracy. In the case of the success rate curve, the area ratio is 0.8831 and the accuracy of the model is $88.31 \%$. In the case of the prediction rate curve, the area ratio is 0.8468 and the prediction accuracy is $84.68 \%$.

\section{RESULTS}

The relationship between landslide occurrence and landslide-related factors by using the frequency ratio method is presented quantitatively in Table 1 . The ratio value indicates how strong the spatial relationship is between a landslide occurrence and landslide-related factor's classes. The value 1 is an average value.
However, when the FR value is greater than 1 , then the percentage of the landslide area in the class is higher than the percentage of the class in the total area which indicates a strong relationship between landslides and the factor's class, whereas when the value is lower than 1 it means a weak relationship. The landslide susceptibility map constructed by LRM is shown in Fig 4. Based on this map, the study area was classified into five classes of susceptibility viz. very low susceptibility, low susceptibility, moderate susceptibility, high susceptibility and very high susceptibility. The percentage distributions of the classified susceptibility classes are shown in Fig. 5

\section{DISCUSSION}

Analysis was carried out to assess the influence of the slope gradient on landslide occurrence and the results showed increasing in FR value as slope angle increases. From the results, we can see that slope angles less than 15 have a ratio lower than 1 , which indicates low probability of landslide occurrence. This is because there is lower shear stresses in soil for gentle slopes so a low frequency of landslides is expected. Whereas soils at high slope gradient areas have high shear stresses therefore they are expected to have high frequency of landslides. At slopes range between 15-25 the ratio is 1 . This value indicates a moderate probability of a landslide occurring. For slopes with angles range between 25-45 the ratios were $>1.9$, indicating a high probability of landslide occurrence. Above slope 45 the ratio decreased to 0.85 , which refer low landslide susceptibility. This result could be interpreted as such slopes covering a small area (5.8\%) are steep natural slopes resulting from outcropping bedrock, which usually have low susceptible to shallow landslides.

From the eight aspect classes, the slope aspects showed high susceptibility to landslides were towards NW, S, N and SW (Table 1) with ratios 1.43, 1.3, 1.26 and 1.16 respectively, whereas the hill slopes facing other directions are low susceptible to landslides with a ratio $<1$. This could be interpreted as most of the landslides occurred perpendicular to the highway which takes the direction east -west in general. In the case of relationship between landslide occurrence and lithology, the phyllite and slate unit was found to be the most susceptible unit having the highest frequency ratio equal to 1.98. Other units showed a high probability of landslide occurrence with a ratio $>1$ were chert, shale, slate unit, granite and metasediments, whereas the landslide occurrence was lower in the rest of lithological units having a low-frequency ratio $(\mathrm{FR}<1)$. 
Considering the elevation factor, in fact, the results of the analysis showed that higher values of 2.11, 1.4 and 1.14 are found in different elevations ranges from $<200 \mathrm{~m}, 400-600 \mathrm{~m}$ and $>1000 \mathrm{~m}$ respectively confirming that this factor does not show a significant trend to indicate a strict relationship between elevation and landslide occurrence in the area.

In the case of lineaments, high and very high lineaments density classes range from $1.5 \mathrm{~km} / \mathrm{km}^{2}$ to $2.5 \mathrm{~km} / \mathrm{km}^{2}$ (Table 1) are the most susceptible classes $(\mathrm{FR}>4)$. Lineaments, as linear morpho-tectonic features of the terrain, are the major discontinuities in the area under investigation. They are one of the important factors control sliding (planar and wedge) and toppling failures. In both cases the rupture occur mainly along existing discontinuities and usually interest an external portion of rock mass. The possibility to landslide is directly influenced by orientation of discontinuities and of slopes and of course, by mechanical strength of discontinuities (Andrea et al., 2010)

Roads network show the strongest relationship with landslide occurrence. The landslide frequency increases as the distance from roads decreases. At a distance of $<300 \mathrm{~m}$, the ratios were $>9.58$ indicating a very strong relation with landslide occurrence, whereas at distances $>300 \mathrm{~m}$, the ratios were $<1$, indicating a weak relationship.

Comparing drainage density with landslide occurrence showed that drainage density between 1.752 $2.629 \mathrm{~km} \mathrm{~km}^{-2}$, which classified as low to medium drainage density classes, are the most susceptible for landslide occurrence (FR > 1.7), whereas high and very high density classes are less susceptible for landslide occurrence $<1$. This can be attributed generally to the fact that low drainage density indicates high porosity of rocks and soils and this leads to a high water infiltration which increases the shear stress and decreases the shear strength in the soil of slopes as well as it builds up the water pressure in the rock mass of a slope and simultaneously increases the depth of weathering in rocks.

The correlation of strata bedding angle with landslide occurrence map showed that areas with strata bedding angle higher than $15^{\circ}$ are only high susceptible to landslides( FR $>1$ ) whereas in the case of foliation the only class with angle between $35^{\circ}-45^{\circ}$ is highly susceptible to landslides (FR>1.4).

In the case of the relationship between landslide occurrence and soil type, the ratio was higher in Siltsandy soils $(\mathrm{FR}>1)$ and lower in Sand-silty soils $(\mathrm{FR}<1)$.

\section{CONCLUSION}

In this study the evaluation of relative importance of each factor to landslide occurrence has been established by applying frequency ratio model. The analysis performed has revealed that different factors have different influence on landslides occurrence. The most important parameters have been pointed out above the others were: distance from road, lineament density and slope gradient. Other factors such as litho logy, soil and slope aspect showed a high importance as well.

Moreover, for each factor, only some classes were found to play a very important role in the occurrence of landslides.The most contributing classes to landslide were found as follows: areas under $300 \mathrm{~m}$ distance from the road, lineament density $>1.5 \mathrm{~km} \mathrm{~km}^{-2}$ (high and very high density), elevation $>1000 \mathrm{~m}$, slope gradient between 35-45, with phyllite and slate lithological unit. Silt-sandy soil, low density drainage and strata bedding angle $>15$, were also found among the classes influencing landslide occurrence. Based on the LSI values the area has been divided into five zones of susceptibility, namely very low (20.03\%), low (32.69\%), moderate (28.21\%), high (15.75\%) and very high (3.29\%).

Area Under the Curve (AUC) showed high prediction accuracy for the proposed model (84.68 \%.) indicating a high accuracy of the produced landslide prediction map. The map could be used by decision makers as basic information for slope management and land use planning to reduce damage caused by existing and future landslides by means of prevention and mitigation.

\section{REFERENCES}

Andrea, F., G. Anrea and M. Giuseppe, 2010. Rock slopes failure susceptibility analysis: from Remote Sensing measurements to geographic information system raster modules. Am. J. Environ. Sci., 6: 489-494. DOI: 10.3844/ajessp.2010.489.494

Huat, B.B.K. and J. Suhaimi, 2005. Evaluation of slope assessment system in predicting landslides along roads underlain by granitic formation. Am. J. Environ. $\quad$ Sci., $\quad 1: \quad 90-96 . \quad$ DOI: 10.3844/ajessp.2005.90.96

Jamaludin, S., B.B.K Huat and H. Umar, 2006. Evaluation of slope assessment systems for predicting landslides of cut slopes in granitic and meta-sediment formations. Am. J. Environ. Sci., 2: 135-141. DOI: 10.3844/ajessp.2006.135.141

Mancini, F., C. Ceppi and G. Ritrovato, 2010. GIS and statistical analysis for landslide susceptibility mapping in the Daunia area, Italy. Nat. Hazards Earth Syst. Sci., 10: 1851-1864. DOI: 10.5194/nhess-10-1851-2010

Nandi, A. and A. Shakoor, 2010. A GIS-based landslide susceptibility evaluation using bivariate and multivariate statistical analyses. Eng. Geol., 110: 11-20. DOI: 10.1016/j.enggeo.2009.10.001 
Pradhan, B., 2010a. Landslide susceptibility mapping of a catchment area using frequency ratio, fuzzy logic and multivariate logistic regression approaches. J. Indian Soc. Remote Sens., 38: 301-320. DOI: $10.1007 / \mathrm{s} 12524-010-0020-\mathrm{z}$

Pradhan, B., 2010b. Use of GIS-based fuzzy logic relations and its cross application to produce landslide susceptibility maps in three test areas in Malaysia. Environ Earth Sci., DOI: 10.1007/s12665-010-0705-1

Pradhan, B. and S. Lee, 2010. Delineation of landslide hazard areas on Penang Island, Malaysia, by using frequency ratio, logistic regression and artificial neural network models. Environ Earth Sci., 60: 1037-1054. DOI: 10.1007/s12665-009-0245-8

Pradhan, B., S. Lee and M.F. Buchroithner, 2010. A GIS-based back-propagation neural network model and its cross-application and validation for landslide susceptibility analyses. Comput. Environ. Urban Sys., 34: 216-235. DOI: 10.1016/j.compenvurbsys.2009.12.004
Poudyal, C.P., C. Chang, H.J. Oh and S. Lee, 2010. Landslide susceptibility maps comparing frequency ratio and artificial neural networks: A case study from the Nepal Himalaya. Environ Earth Sci., 61: 1049-1064. DOI: 10.1007/s12665-009-0426-5

Regmi, N.R., J.R. Giardino and J.D. Vitek, 2010. Assessing susceptibility to landslides: Using models to understand observed changes in slopes. Geomorphology, 122: 25-38. DOI: 10.1016/j.geomorph.2010.05.009

Sulaiman, W.N.A. and M.H. Rosli, 2010. Susceptibility of shallow landslide in fraser hill catchment, pahang Malaysia. Environment Asia, 3: 66-72. 